\title{
Aids Pandemic: Traditional Practices Increasing Risk of HIV Infections in South Africa
}

\author{
Nemutandani MS ${ }^{1 *}$, Adedoja $\mathrm{D}^{2}$ and Nemutandani $\mathrm{V}^{3}$
}

${ }^{1}$ Department of Public Health, Polokwane Campus, University of Limpopo, South Africa

${ }^{2}$ Dental Specialist Facility, Health, Polokwane Campus, University of Limpopo, South Africa

${ }^{3}$ School of Humanities and Social Sciences, University of Venda, B SW Hons, South Africa

\begin{abstract}
Traditional bare-knuckle fist (boxing without protective gloves and mouth guards) fighting practices in South Africa may constitute a subtle route of HIVIAIDS spread. The fighters without protective barriers are exposed to the blood products and body fluids of each other during such tournaments. Little or no study exists about the knowledge and perceptions of the bare-knuckle fighters on the risk of acquiring HIV infection during such sport in South Africa.

Methods: Focus group discussion with participants and interviews with organizers were conducted to determine the knowledge and perceptions on risk for HIV infection and the motivating factors among the fighters.

Results: It was found that the fighters have inadequate knowledge about possible HIV transmission during such bouts. Apart from fun and entertainment, upholding ancestral tradition was a strong factor for participation in bareknuckle fighting.

Conclusion: The knowledge and perceptions on HIV infections among the fighters appear inadequate. They rely on protective power of" muti" (magical wands, powder and herbs) against injury and HIV infections. There is a need for multifaceted approach to prevent possible spread of HIV and other blood-borne infections among the fighters and its ripples effect on the community.
\end{abstract}

Keywords: Traditional practices; Bare-knuckle fist fighting; Risk of HIV infection

Human Immunodeficiency Virus (HIV) infection and Acquired Immunodeficiency Syndrome (AIDS) remains a global public health problem with huge impact on the health care system, family system and socio-economic consequences [1]. It is estimated that about $95 \%$ of the people living with HIV are in the developing countries, where the prevalence rates among adults is between 20-30 [2]. The World Health Organization, confirmed that $65 \%$ of estimated 39.5 million people infected with HIV globally are in sub-Saharan Africa. Furthermore, about two-third of the newly diagnosed cases resides in Africa and the likelihood of sub-Saharan adult to acquire HIV infection is 10 times higher than for an American adult and 20 times higher for Western Europe adult [3].

In 2012, South Africa accounted for about 6.1 million of all people living with HIV and AIDS in the world [4]. With more than 240,000 deaths due to AIDS in 2012, South Africa has more than 2.5 million orphans due to AIDS aged 0 to 17 years. This figure may be an underestimation as the true cause of death is not always disclosed because of stigmatization [4]. This epidemic continues to grow in South Africa despite efforts to control it. Although the majority of South Africans are familiar with HIV/AIDS, risky practices are still widespread among young people especially in rural areas [3]. Pervasive traditional practices and cultural beliefs that are likely to expose fighters to infectious diseases such as HIV $[5,6]$, indicate the need for improved intervention programs in South Africa.

The traditional bare-knuckled fighting (boxing without protective gloves and mouth guards), commonly known as Musangwe is an ancient sport practiced by young African men whilst dipping their cattle. The fight among the bulls as the dip, and whose bull won the fight was soon be replaced by men fighting each other. It involves the use of bare knuckle fists, elbows, knees and head butts [7].
Recent report indicated that there is a growing trend among rural men to participate in traditional bare- fist fighting sport in South Africa [7]. Unlike modern competitive contact sport such as boxing and karate [8,9], bare fist fighters are neither protected, screened for infectious diseases nor examined for their health status, weight, height and suitability for the opponent. Soft tissue injuries with profuse bleeding such as contusion, lacerations, abrasions are common during contact sports (Figures 1 and 2) and could result in transmission of blood borne infectious diseases if protective devices are not worn [10]. Thus traditional bare- knuckle fist fighting could be a silent mode of HIV transmission in South Africa which heavily laden with HIV/AIDS.

It has been observed that behaviour change and community engagement appear to be the most effective method to prevent the spread of HIV/AIDS [11,12]. In achieving behavioural change, perceived threat of contracting the disease/condition is known to produce best result $[11,12]$. However, studies have also shown that many people tend to believe in their own invulnerability to AIDS, a phenomenon widely referred to as optimism bias $[7,11,12]$. The reasons for such erroneous belief is rooted in misconception, ignorance, cultural beliefs and denial $[11,12]$. There is paucity of information on the knowledge and perceptions of traditional fist fighters on the risk

*Corresponding author: Nemutandani MS, Polokwane Campus, University of Limpopo, South Africa, Tel: +27 86 6635218; Fax: +27 15287 5473; E-mail: Ve2si@yahoo.com, ve22si@gmail.com

Received December 26, 2013; Accepted January 02, 2014; Published February 08, 2014

Citation: Nemutandani MS, Adedoja D, Nemutandani V (2014) Aids Pandemic: Traditional Practices Increasing Risk of HIV Infections in South Africa. J Clin Res Bioeth 5: 173. doi:10.4172/2155-9627.1000173

Copyright: (C) 2014 Nemutandani MS, et al. This is an open-access article distributed under the terms of the Creative Commons Attribution License, which permits unrestricted use, distribution, and reproduction in any medium, provided the original author and source are credited. 


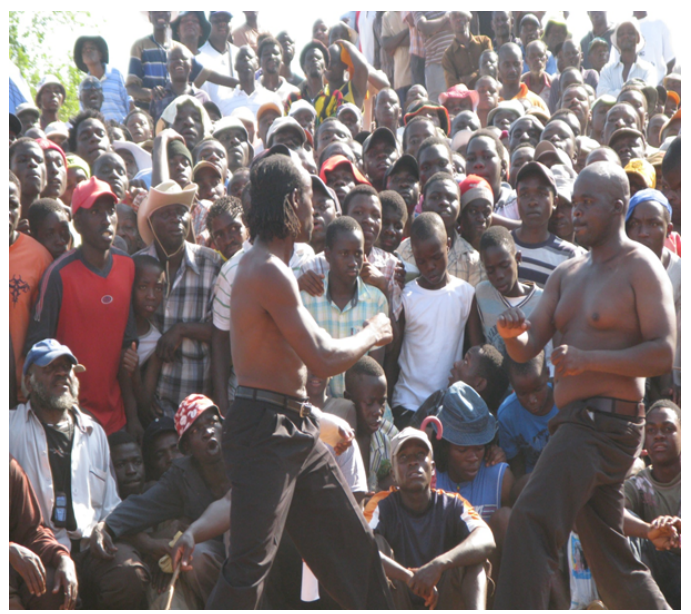

Figure 1: Adult males fighting during the traditional fist fighting tournament.

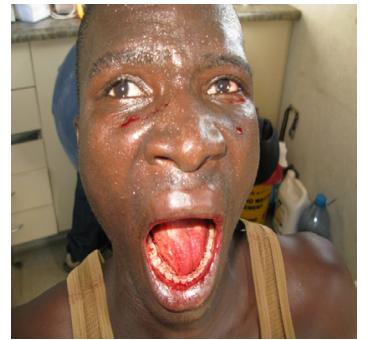

Figure 2: Traditional fist fighter with facial bruises and bleeding after the fight.

of HIV infections. Therefore, it becomes pertinent to investigate the knowledge and perceptions of this group of our population on HIV/ AIDS transmission and acquisition during the tournament they participate twice in a year.

\section{Materials and Methods}

Qualitative research approach was adopted to determine the knowledge and perception of the bare-knuckle fist fighters on spread of HIV/AIDS during the fight and what are the motivating factors for participation in such tournaments. The research protocol was approved by the Ethics committee of the University of Limpopo, Polokwane and permission given by the sport organizers. Study participants were all bare fist fighters participating in the sport between December 2012 and October 2013. Before the fights, tournament organizers introduced researchers to the participants. The selection of fighters was guided by tournament organizers and supported by fighters from same village or town.

Organizers selected one fighter per area. The selected fighter should be a team leader of fighters from his village or town, and has been fighting for more than five years. Seven focus group discussions (FGD) consisting of nine participants each and face to face individual interviews with five (5) tournament organizers were held. Three calibrated investigators (moderator, note taker and assistant moderator) conducted all interviews before the fights using semi structured questionnaires with four main FGD questions:

- What are your perceptions about the risk of HIV infections during the fight?
- How do you protect yourself from getting injured during the fights?

- What is your opinion about the introduction of HIV testing for the participants?

- What are the motivating factors for participating in bare fist tournaments?

The FGD was audiotaped to ensure that the participant's responses were quoted verbatim. The FGD conducted in mobile clinic lasted approximately 55 minutes. Modified participant observation and hand written field notes were also taken as data sources. After each bout, fighters were seen in mobile clinic for clinical examination.

Minor injuries were treated and more serious injuries were referred for management in the hospital.

\section{Data Management and Analysis}

The final transcripts for analysis were based on the transcribed audiotapes and handwritten notes. These data were analyzed using a grounded theory approach, which begins with the careful reading and re-reading of transcribed transcripts. From this, coding schemes of responses are developed that are used to identify common themes. Three authors (Simon, David, Veronica) independently developed coding schemes, and identified themes by consensus. The themes thus identified were evaluated by all authors for consistency and redundancy. Direct quotes arising from the discussion are presented to support identified themes. To ensure anonymity, participants are given pseudonyms.

In order to increase credibility of the study, triangulation method was used. The triangulated data sources were assessed against one another to cross-check data and interpretation. The underlying assumption is that, because various methods complement each other, their respective shortcomings can be balanced out.

\section{Results}

\section{HIV messages, cultural practices and perceptions on risk of HIV infections}

The group had different views on the subject. There was a strong feeling that HIV testing was not necessary. Some believed that they are protected from HIV infections by muti while others doubt efficacy of such magical power in protecting against HIV acquisition. Maanda: "From the point that I am looking at... the knowledge that I have as a community member. HIV exists, but I don't think I can get it, my muti protects me". [Interjected, shaking the head] Joe: "...If you get my blood and I am HIV+, you will have AIDS". James: "Your muti is useless, 30 or 40 mineworkers died in Marikana...sangoma misled them....were killed".

The dominant views, however, is that of belief that muti offer reliable protection against spread of HIV and therefore consider HIV testing, use of protective devices, and other measures to prevent transmission unnecessary.

\section{Motivating factors for participating in bare fist tournaments}

The main motivating factor other than fun and entertainment was the fulfillment of old tradition practiced by the ancestors. Boysen: "Whether I win or lose...I feel very fulfilled and feeling of pride that I am walking in the footsteps of my forefathers" 
Diesel: “...I have been fighting since the age of 7 years with no money...I have lost three teeth, look here, you see [yes, group nodding their heads in agreement].... I am a brave man; it's a sport for man". The participants' motivating factors go beyond winning and or loosing. One participant (tournament organiser) indicated that "it appeases the ancestors when the men come together to practice their traditions". Rex: ".....traditional health practitioners and community leaders are part of organising team”.

\section{Discussion}

There are many published studies which document the transmission of blood borne pathogens such as Hepatitis and HIV through open skin in sporting events [13-15]. The likelihood of transmission is increased in the absence of protective measures as practiced by bare-fist knuckle fighters.

These fighters demonstrated poor knowledge on the risk of transmission of blood borne pathogens such as HIV and hepatitis during the tournament. They rely heavily on protective power of herbs and muti against the spread of HIV and maintain that participation offer them pride in appeasing the ancestor though no monetary, material or trophy rewards.

Many researchers have reported that cultural beliefs and traditional practices constitute an obstacle to individual behavior change and community engagement as a method of preventing spread of HIV/ AIDS [11,12,16-19]. It is possible that the fighters may change their attitude if they are made to see the danger of acquiring HIV during the tournament.

The reported gaps in HIV/AIDS knowledge and participants' heath beliefs and practice are usually embedded in social conditions in which they live and work [20]. Such beliefs and practices have effect on their decisions and behavior [17,18]; which may block any intervention messages from health providers in printed and broadcast media.

Several community factors such as denial of HIV existence, community isolation and discrimination of infected individuals, evil spirits causing diseases, protective muti and ancestors punishing wrong doers are probably contributing to low HIV testing $[16,17,20]$. The attitude of participants in bare-knuckle fist fighters fit into most of these factors.

Published reports indicated that fist fighters could be cross infected if they sustain laceration and bleeding during the sport $[14,15]$. The dearth of publications on transmission of HIV/AIDS through contact sports may be due to effectiveness of screening procedures and protective devices used. However, this could not be said of bare knuckle sport as observed in this study. We are of the opinion that the risk of HIV/AIDS could be real in bare knuckle fist fighting. The increasing number of fighters participating in the tournament should be a matter of concern to health authorities [7]. In sub-Saharan Africa, where the prevalence of HIV exceeds $30 \%$, and with no concrete evidence of declining $[4,5]$, every avenue of spreading the disease must be blocked. The main ethical challenge would be how to introduce screening of fighters and the use of protective devices without changing the rules of the game and modernization of traditional practices and the culture.

\section{Conclusion}

The participants in the study prefer to maintain their traditional practices and cultural beliefs in fist tournaments. Their knowledge and perception of risk of transmitting HIV/AIDS during the tournament is inadequate. Of major concern is their reliance on muti for protection and negative attitude towards HIV testing and use of protective devices. There is a need for a multifaceted and multilevel approach to help prevent spread of HIV through this insidious route. This will include education and government participation in the sport.

Researchers acknowledge limitations of our study: (1) convenience sample may not be representative of the population being studied. It can lead to under-representation or over-representation of particular groups within the sample, which often lead to biases results.(2) Our presence during FGD may have affected and or influencedthe fighters' responses, and (3) generalizability of the results.

\section{Acknowledgement}

Authors would like to thank traditional fist fighters and tournament organisers

\section{References}

1. Beaudoin CE (2007) HIV prevention in sub-Saharan Africa: a multileve analysis of message frames and their social determinants. Health Promot Int 22: 198-206

2. World Health Organisation (2010) France: WHO Health Statistics, WHO; 2010

3. Joint United Nations Programme on HIVIAIDS (UNAIDS)

4. UNAIDS. Report on the Global HIVIAIDS Epidemics, 2012. Geneva: UNAIDS.

5. Department of Health. HIV \& AIDS and STI National Strategic Plan 2007-11. Pretoria: Department of Health.

6. UNAIDS. 2006 report on global AIDS epidemic Geneva: UNAIDS.

7. Nemutandani MS, Adedoja D, Nemutandani V (2012) Orofacial injuries among traditional bare-fisted fighters. SADJ 67: 164-167.

8. Corrado D, Schmied C, Basso C, Borjesson M, Schiavon M, et al. (2011) Risk of sports: do we need a pre-participation screening for competitive and leisure athletes? Eur Heart J 32: 934-944.

9. Dorman JM (2000) Contagious diseases in competitive sport: what are the risks? J Am Coll Health 49: 105-109.

10. Kordi R, Wallace WA (2004) Blood borne infections in sport: risks of transmission, methods of prevention, and recommendations for hepatitis $B$ vaccination. Br J Sports Med 38: 678-684.

11. Tenkorang EY, Adjei JK, Gyimah SO (2010) Perceptions of HIVIAIDS risk and sexual Risk-Taking of young people in Ghana. Can J Dev Stud 31: 439-457.

12. Seyde E, Tall E, Wlegman O (1990) Risk-appraisal. Outcome and self-efficacy expectancies: cognitive factors in preventing behaviour related to cancer. Psychol Health 4: 99-109.

13. Bourlière M, Halfon $P$, Quentin $Y$, David $P$, Mengotti C, et al. (2000) Covert transmission of hepatitis $C$ virus during bloody fisticuffs. Gastroenterology 119 : 507-511.

14. Ippolito G, Del Poggio P, Arici C, Gregis GP, Antonelli G, et al. (1994) Transmission of zidovudine-resistant HIV during a bloody fight. JAMA 272 433-434.

15. O'Farrell N, Tovey SJ, Morgan-Capner P (1992) Transmission of HIV-1 infection after a fight. Lancet 339: 246.

16. South African Broadcasting Corporation: News. Marikana miners' strike

17. Chao LW, Gow J, Akintola G, Pauly M (2010) HIVIAIDS stigma attitudes among educators in KwaZulu-Natal, South Africa. J Sch Health 80: 561-569.

18. Opaneye A, Ochogwu S (2007) The challenges of involving traditional healers in HIVIAIDS care. Int J STD AIDS 18: 68-69.

19. Ransom J, Johnson AF (2009) Key findings: a qualitative assessment of provider and patient perceptions of HIVIAIDS in South Africa. Soc Work Public Health 24: 47-59.

20. Giarelli E, Jacobs LA (2003) Traditional healing and HIV-AIDS in KwaZuluNatal, South Africa. Am J Nurs 103: 36-46. 